\title{
Label-Free Semiquantitative Liquid Chromatography-Tandem Mass Spectrometry Proteomics Analysis of Laryngeal/Hypopharyngeal Squamous Cell Carcinoma on Formalin-Fixed, Paraffin-Embedded Tissue Samples - a Pilot Study
}

\author{
Andras Burian $^{1} \cdot$ Laszlo Lujber ${ }^{1} \cdot$ Imre Gerlinger $^{1} \cdot$ Tamas Jarai $^{2} \cdot$ Eva Orosz $^{1} \cdot$ Lilla Turiak $^{3} \cdot$ Andras Acs $^{3,4}$. \\ Zoltan Hegedus $^{5,6} \cdot$ Aniko Konigne Peter $^{7} \cdot$ Tamas Tornoczki $^{8} \cdot$ Katalin Gombos $^{9} \cdot$ Laszlo Mark $^{6,10}$
}

Received: 25 July 2019 / Accepted: 11 June 2020 / Published online: 21 June 2020

(C) The Author(s) 2020

\begin{abstract}
Squamous cell carcinoma (SCC) of the head and neck region is the sixth most frequent malignancy with high mortality rate. Due to its poor prognosis it is considered a growing public health problem worldwide inspite of existing treatment modalities. Thus, early diagnosis of new diseases and recurrences is emerging on one hand, but on the other hand troublesome in the lack of reliable tumor markers in this field. The rapid development of proteomics has opened new perspectives in tumor marker discovery. Liquid chromatography/mass spectrometry (LC/MS) as the gold standard in proteomics enables the semi-quantitative analysis of proteins within various tissues. Abundance differences between tumor and normal tissue also can be interpreted as tumor specific changes. The aim of this study was to identify potential tumor markers of laryngeal/hypopharyngeal SCC by revealing abundance changes between cancerous and the surrounding phenotypically healthy tissue. After separating the phenotypically cancerous and healthy parts of formalin-fixed paraffin-embedded tissues, each sample underwent protein recovery process and tryptic digestion for label-free semi-quantitative LC/MS analysis. Eight proteins showed significantly higher abundance in tumor including tenascin, transmembrane emp24 domain-containing protein 2, cytoplasmic dynein light chain 1, coactosin-like protein, small proline-rich protein 2D, nucleolin, U5 small nuclear RNP 200-kDa helicase and fatty aldehyde dehydrogenase. Desmoglein-1 and keratin type I cytoskeletal 9 were down-regulated in tumor. Using Ingenuity Pathway Analysis we mapped the signaling pathways these proteins play role in regarding other tumors. Based on these findings these proteins may serve as promising biomarkers in the fight against laryngeal/hypopharyngeal SCCs.
\end{abstract}

Keywords Biomarker discovery $\cdot$ Laryngeal cancer $\cdot$ LC/MS $\cdot$ Squamous cell carcinoma $\cdot$ Proteomics

Laszlo Mark

laszlo.mark@aok.pte.hu

1 Clinical Centre, Department of Otorhinolaryngology and Head and Neck Surgery, University of Pecs, Munkacsy M Str 2, Pecs H-7621, Hungary

2 Tolna County Balassa Janos Hospital, Beri Balogh Adam Str 5-7, Szekszard H-7100, Hungary

3 MS Proteomics Research Group, Research Centre for Natural Sciences, Hungarian Academy of Sciences, Magyar tudosok Blvd 2, Budapest H-1117, Hungary

4 Ph.D. School of Pharmaceutical Sciences, Semmelweis University, Ulloi Str 26, Budapest H-1085, Hungary
5 Biological Research Centre of the Hungarian Academy of Sciences, Institute of Biophysics, Temesvari Blvd 62, Szeged H-6726, Hungary

6 Medical School, Institute of Biochemistry and Medical Chemistry, University of Pecs, Szigeti Str 12, Pecs H-7624, Hungary

7 Medical School, Institute of Bioanalysis, University of Pecs, Honved Str 1, Pecs H-7624, Hungary

8 Medical School, Institute of Pathology, University of Pecs, Szigeti Str 12, Pecs H-7624, Hungary

9 Clinical Centre, Department of Laboratory Medicine, University of Pecs, Ifjusag Str 13, Pecs H-7624, Hungary

10 MTA-PTE Human Reproduction Research Group, Edesanyak str. 1, Pecs H-7624, Hungary 


\section{Introduction}

Head neck squamous cell carcinoma (HNSCC) is the 6th most frequent malignancy [1] related with nicotine and alcohol abuse [2]. Its incidence is three-fold higher in males. Due to the aspecific symptoms most HNSCCs are diagnosed with advanced stage indicating growing public health problem worldwide The low 5-year overall survival rate has not changed significantly in the past decade despite surgical and oncological innovations [3].

Thus, early diagnosis and better understanding of tumor behavior is essential. HNSCCs probably produce several proteins that could be utilized as tumormarkers. In possession of reliable markers not only screening and early recognition, but early detection of recurrence could be achieved. In addition, some markers may serve as promising targets for biological therapies.

Due to rapid proteomics development, a new way has opened in biomarker discovery. Beside evaluating epigenetic modifications, on-tissue protein distribution investigation and protein imaging also became available [4]. As potential biomarkers are mostly unknown, labeling can not be used in discovery contrary to label-free semiquantitative methods. Without labeling, intensity of distinct peptides appropriately follows their abundance changes. Nevertheless, label-free methods are more cost-efficient. LC/MS possesses these advantages. Its high throughput feature also makes it powerful in protein discovery. Initially, proteomic analysis of solid tumors with mass spectrometry (MS) was available only on fresh frozen samples. Therefore, growing demand for analysis of formalin fixed paraffin embedded (FFPE) tissue samples appeared. Development of tissue preparation protocols enabled the elimination of formaldehyde induced protein cross-linkings disturbing MS. Overcoming this formerly limiting factor, an invaluable perspective has opened in retrograd analysis due to broad histological sample archives used in daily clinical practice.

The present study aims to investigate protein abundance differences between laryngeal/hypopharyngeal squamous cell carcinoma (LHSCC) and phenotypically normal tissue on FFPE samples to identify potential tumor markers. Furthermore, based on the literature and Ingenuity Pathway Analysis (IPA), we aim to map the pathways these proteins take part in other malignant tumors in order to evaluate them as possible candidates for target therapy of HNSCCs in the future.

\section{Material and Methods}

\section{Patients}

Sixteen consenting patients (16 males, median age 61 yrs., range from $45 \mathrm{yrs}$. to $79 \mathrm{yrs}$ ) diagnosed with LHSCC were enrolled. Heavy smoking and regular alcohol consumption were reported in all cases. All tumors were advanced primary cases (stage III-IV.A). Exclusion criteria included non-SCC histology, HPV positivity, previous oncological treatment and recurrence or second primary tumor.

\section{Method}

Clinical examination included biopsy from all tumors for diagnosis prior to treatment. Biopsy samples were fixed in formalin followed by paraffin-embedding, sectioning and hematoxylin-eosin (HE) staining. Histological examination confirmed HNSCC in all cases.

For research purposes, all corresponding paraffin-embedded tissue blocks were retrieved and further sections $(15 \mu \mathrm{m}$ thickness) were made from original blocks and placed to conventional histological plate without staining. In addition, another HE stained section ( $7 \mu \mathrm{m}$ thickness) was made from blocks with one obvious malignant field marked by the pathologist on the contralateral side of the plate. Based on this marking, identical part of each plate containing unstained paraffin-fixed section was drawn around in the same way. Deparaffinization was performed by washing the unstained slides with xylol, ethanol $90 \%(\mathrm{~m} / \mathrm{m})$, ethanol $70 \%(\mathrm{~m} / \mathrm{m})$, ethanol $50 \%(\mathrm{~m} / \mathrm{m})$ and $50 \mathrm{mM}$ ammonium-bicarbonate, respectively. Antigen retrieval was performed with $100 \mathrm{mM}$ Tris-HCl buffer $\left(97{ }^{\circ} \mathrm{C}, 30 \mathrm{~min}\right)$. According to the marked field lining histologically obvious malignant part, the tissue was microdissected with a fine needle and collected to $2 \mathrm{ml}$ Eppendorf tube containing SDS lysis buffer. Tumor adjacent normal tissue was also microdissected and each sample was incubated in the lysis buffer $\left(97^{\circ} \mathrm{C}, 30 \mathrm{~min}\right)$. After centrifugation ice cold absolute ethanol was added to the supernatant with 9 volume surplus. Samples were kept at $4{ }^{\circ} \mathrm{C}$ overnight for protein precipitation. The pellet was washed twice with absolute ethanol, proteins were solubilized with $8 \mathrm{M}$ urea. Reduction and alkylation were followed by overnight trypsin digestion. The resulting tryptic peptides were cleaned using Pierce C18 spin columns (Thermo Fisher Scientific, Waltham, MA). The MS used for analysis was a Bruker mAXIS II ETD Q-TOF (Bruker Daltonics, Bremen, Germany) coupled to an Ultimate 3000 nanoRSLC system (Dionex, Sunnyvale, CA, USA). Samples were injected on an Acclaim PepMap100 C-18 trap column $(100 \mu \mathrm{m} \times 20 \mu \mathrm{m}$, Thermo Scientific, Sunnyvale, CA, USA) online coupled to an ACQUITY UPLC M-Class Peptide BEH C18 column $(130 \AA, 1.7 \mu \mathrm{m}, 75 \mu \mathrm{m} \times 250 \mathrm{~mm}$, Waters, Milford, MA, USA). Peptides were separated at $48{ }^{\circ} \mathrm{C}$ with a flow rate of $300 \mathrm{nl} / \mathrm{min}, 4 \%$ solvent $\mathrm{B}$ from 0 to $11 \mathrm{~min}$, followed by a 120 min gradient to $50 \%$ solvent B. Solvent A consisted of water $+0.1 \%$ formic acid, while Solvent B was acetonitrile $+0.1 \%$ formic acid. The injected sample amount was $0.5 \mu \mathrm{g}$. Sample ionization was achieved in the positive electrospray ionization mode via a CaptiveSpray nanoBooster ionsource. The capillary voltage was $1300 \mathrm{~V}$, the nanoBooster pressure was 0.2 Bar, drying gas was $150{ }^{\circ} \mathrm{C}$, the flow rate was $3 \mathrm{l} / \mathrm{min}$. External mass calibration was done using the low concentration tuning mix 
from Agilent technologies via direct infusion. Internal mass calibration was performed via lock mass for each run using sodium formate. The MS spectra were recorded with a fix cycle time (2.5 s) over the mass range of $\mathrm{m} / \mathrm{z} \quad 150-2200$ at $3 \mathrm{~Hz}$ with a minimal precursor mass of $\mathrm{m} / \mathrm{z} 322$. The CID was performed at $16 \mathrm{~Hz}$ for abundant precursors and at $4 \mathrm{~Hz}$ for ones of low abundance. Singly charged peptides were excluded from analysis, only multiple charged peptides were chosen for fragmentation. Collision energy for precursor signals was set automatically followed by the manufacturer's recommendations based on the isolation $\mathrm{m} / \mathrm{z}$, isolation mass range width and ion charge state. Active exclusion of $2 \mathrm{~min}$. After 1 spectra was used except if the intensity of the precursor was elevated threefold. For protein analysis raw data were recalibrated using the Compass DataAnalysis software 4.3 (Bruker Daltonics, Bremen, Germany). Data were processed by the ProteinScape 3.0 software (Bruker Daltonik GmbH, Bremen, Germany). Proteins were identified by searching against the human Swissprot database (2015_08) using the Mascot search engine version 2.5 (Matrix Science, London, UK) applying the following search parameters: 7 ppm peptide mass tolerance, $0.05 \mathrm{Da}$ fragment mass tolerance, 2 missed cleavages, carbamidomethylation of cysteines as fixed modification, deamidation (NQ) and oxidation (M) as variable modifications and proteins were identified using $1 \%$ FDR limit. Label-free quantitation (LFQ) was then performed using MaxQuant (software version 1.5.3.30), applying default parameters. MaxQuant analysis searched only for proteins identified previously by Mascot. Each LC-MS/MS run was aligned using the "match between runs" feature (match time window $0.8 \mathrm{~min}$, alignment time window $15 \mathrm{~min}$ ). The acquired data underwent discriminant analysis and paired sample t-test searching for proteins most characteristically describing tumor and normal tissue. Bioinformatic analysis were performed by IPA software (Ingenuity Databases, Mountain View, CA, USA) to place identified proteins in known signalling pathways.

\section{Results}

1164 proteins were identified with at least 2 unique peptides among the samples. Discriminant analysis revealed 18 proteins describing either the tumor or normal tissue group. Paired sample t-test were used to test for statistical significance between each pair regarding these most descriptive 18 proteins (Table 1). The $p$ value was determined 0,1 considering the low number of sample pairs of coherent tumor and normal tissue $(n=16)$. Thus, 8 proteins showed significantly higher density in tumor including tenascin (TNC), transmembrane emp24 domain-containing protein 2 (TMED2), dynein light chain 1, cytoplasmic (DYNLL1), coactosin-like protein (COTL1), small proline-rich protein 2D (SPRR2D), nucleolin (NCL), U5 small nuclear RNP 200-kDa helicase (SNRNP200) and fatty aldehyde dehydrogenase (ALDH3A2). Two proteins, desmoglein-1 (DSG1) and keratin type I cytoskeletal 9 (KRT9) had significantly higher density in the adjacent phenotipically normal tissue. Data and physiological roles of identified proteins are demonstrated in Table 2.

\section{Discussion}

Despite rapid development of molecular diagnostics, tumormarker discovery is still challenging. In the past few years the interest of tumor research has gradually turned to proteomics highlighting the observation that secreted proteins are as important as tumor genetics. MS coupled with LC is considered as the ,gold standard" quantitative method in tumor protein research. Due to the continuously evolving technical background, growing effort on investigation of HNSCC proteome has also appeared. Initially, studies targeted in vitro cell lines. Analysis of solid tumor tissues opened new ways in tumormarker discovery, as these include the surrounding microenvironment also contributing to the malignant nature of HNSCCs [5]. MS-based protein analysis had been previously possible only on fresh frozen tissue samples with the neccessity of organization steps including planned cryosection and coordination of sample preparation. These drawbacks can be overhelmed by FFPE tissues utilizing deparaffination process [6]. Among existing papers reporting proteomic analysis on FFPE samples, only a few reports address HNSCC [7]. Discovering possible tumor markers can be achieved by finding proteins exclusively expressed by tumor tissue, but protein abundance differences between normal and tumor tissue can also be interpreted as a possible tumor marker. Our aim was to explore protein abundance differences between phenotypically normal and tumor tissue on FFPE laryngealhypopharyngeal tumor samples. To our knowledge no LC/ MS based proteomical studies exist exclusively investigating LHSCC on FFPE samples.

We found eight and two proteins with significantly higher and lower abundance in LHSCC, respectively, compared to adjacent normal tissue (Table 2).

We foremost found TNC, DYNLL1, COTL1, SPRR2D, SNRNP200, TMED2 and ALDH3A2 abundant in LHSCC by LC/MS. Similar to our findings, one LC/MS study also found NCL levels elevated in LHSCC [8].

We first found DSG1 down-regulated in LHSCC with LC/ $\mathrm{MS}$, albeit rather isoform switch among desmogleins seems to be determining in tumor invasivity.

We identified K1C9 down-regulated. One possible explanation for down-regulation is the dedifferentiation. The other probable hypothesis in our opinion is the lack of detectable tryptic peptides of cytokeratins in peritumoral microenvironment due to non-tryptic digestion during invasion.

IPA found no connection between proteins, but we uncovered existing interactions being considered as possible targets for future therapies in LHSCCs (Fig. 1). 


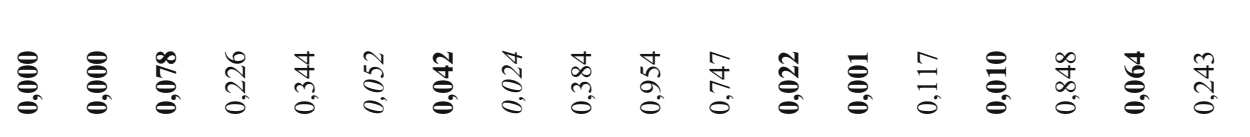

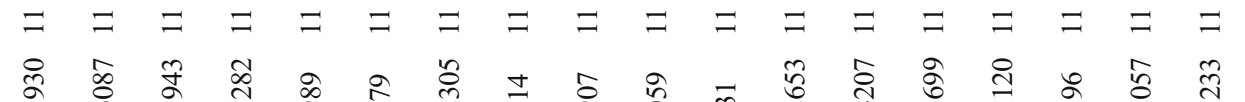

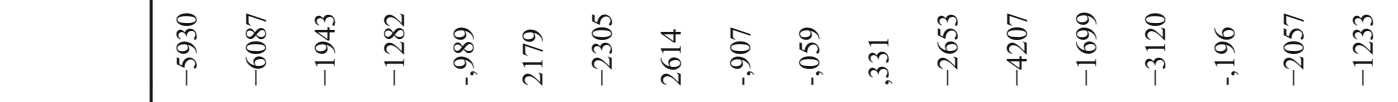

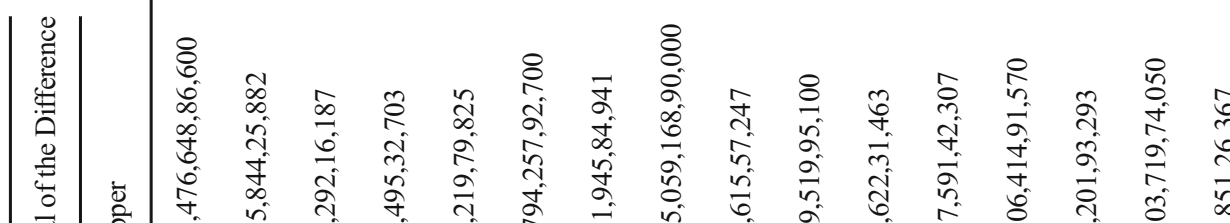

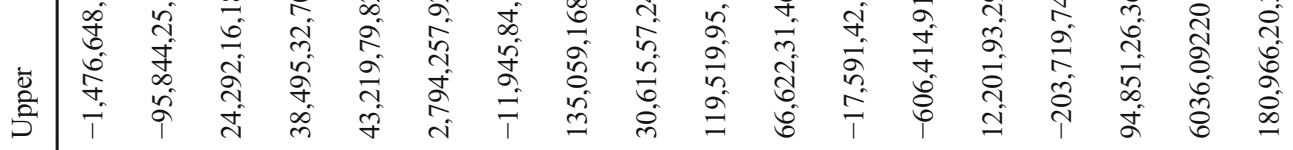

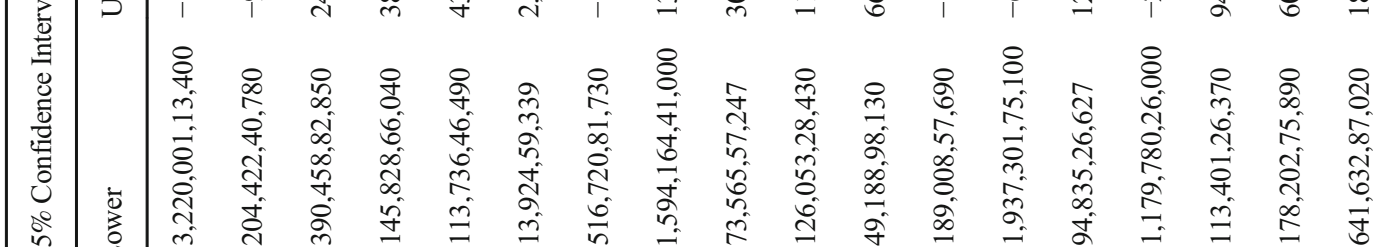


Table 2 Data of identified proteins

\begin{tabular}{|c|c|c|c|c|c|c|c|c|}
\hline $\begin{array}{l}\text { Gene } \\
\text { symbol }\end{array}$ & Accession & Role & $\begin{array}{l}\text { HNSCC related literature } \\
\text { referral }\end{array}$ & IPA findings & $\begin{array}{l}\text { Mascot } \\
\text { score }\end{array}$ & $\begin{array}{l}\mathrm{MW} \\
(\mathrm{kDa})^{*}\end{array}$ & $\begin{array}{l}\sum \mathrm{SC} \\
(\%)^{* *}\end{array}$ & $\sum_{\text {Peptides*** }}$ \\
\hline TNC & $\begin{array}{l}\text { TENA- } \\
\text { HUM- } \\
\text { AN }\end{array}$ & $\begin{array}{l}\text { ECM adhesion, } \\
\text { angiogenesis, EMT }\end{array}$ & $\begin{array}{l}\text { overexpression as adverse } \\
\text { prognostic factor in oral } \\
\text { SCC ( } m R N A \text { expression } \\
\text { analysis) }\end{array}$ & $\begin{array}{l}\text { activating EGFR due to } \\
\text { EGF-like repeats }\end{array}$ & 354 & 240.7 & 8.3 & 13 \\
\hline TMED2 & $\begin{array}{l}\text { TMED2- } \\
\text { HUM- } \\
\text { AN }\end{array}$ & $\begin{array}{l}\text { trafficking between } \\
\text { endoplasmic } \\
\text { reticulum and Golgi } \\
\text { apparat, cytoskeletal } \\
\text { re-arrangement, cell } \\
\text { migration }\end{array}$ & $\begin{array}{l}\text { up- and downregulation in } \\
\text { oral and } \\
\text { hypopharyngeal SCC } \\
\text { (miRNA expression and } \\
\text { gene expression } \\
\text { analysis, low sample } \\
\text { number, } n=5 \text { ) }\end{array}$ & $\begin{array}{l}\text { overexpression mediated by } \\
\text { NFE2L2 (a transcription } \\
\text { factor that may promote } \\
\text { carcinogenesis) }\end{array}$ & 59.1 & 22.7 & 12.2 & 3 \\
\hline DYNLL1 & $\begin{array}{l}\text { DYL1- } \\
\text { HUM- } \\
\text { AN }\end{array}$ & $\begin{array}{l}\text { intracellular } \\
\text { microtubular vesicle } \\
\text { transport, } \\
\text { maintenance of } \\
\text { cytoskeleton }\end{array}$ & $\begin{array}{l}\text { up-regulation under } \\
\text { hypoxic conditions on } \\
\text { FaDuDD HNSCC cell } \\
\text { line }(L C-M S / M S)\end{array}$ & $\begin{array}{l}\text { indirectly facilitating } \\
\text { HGF/c-MET pathway }\end{array}$ & 82.3 & 8 & 21.6 & 5 \\
\hline COTL1 & $\begin{array}{l}\text { COTL1- } \\
\text { HUM- } \\
\text { AN }\end{array}$ & $\begin{array}{l}\text { F-actin binding protein, } \\
\text { cellular motility }\end{array}$ & no reports found & $\begin{array}{l}\text { tumor associated protein in } \\
\text { chemical-induced SCC } \\
\text { model }^{\dagger}\end{array}$ & 72.7 & 15.9 & 5.4 & 3 \\
\hline SPRR2D & $\begin{array}{l}\text { SPR2D } \\
\text { HUM- } \\
\text { AN }\end{array}$ & $\begin{array}{l}\text { function in skin barrier, } \\
\text { wound healing, } \\
\text { quenching of ROS, } \\
\text { terminal } \\
\text { differentiation } \\
\text { marker of stratified } \\
\text { squamous epithel }\end{array}$ & $\begin{array}{l}\text { up-regulated in oral SCC } \\
\text { and NPC (RNA } \\
\text { analysis) }\end{array}$ & no data found & 89.1 & 7.9 & 46.8 & 3 \\
\hline NCL & $\begin{array}{l}\text { NUCL } \\
\text { HUM- } \\
\text { AN }\end{array}$ & $\begin{array}{l}\text { co-factor in } \\
\text { transcription } \\
\text { regulation and RNA } \\
\text { transport }\end{array}$ & $\begin{array}{l}\text { overexpressed in laryngeal } \\
\text { SCC (LC-MS/MS on } \\
\text { snap frozen tissue } \\
\text { samples) }\end{array}$ & $\begin{array}{l}\text { recruiting EGFR mediated } \\
\text { signaling pathways, } \\
\text { facilitating EGFR } \\
\text { cytoplasmic tail } \\
\text { dimerization, direct } \\
\text { binding with SNRNP200 } \\
\text { playing role in RNA } \\
\text { metabolism }\end{array}$ & 316.2 & 76.6 & 17.9 & 11 \\
\hline SNRNP200 & $\begin{array}{l}\text { U520 } \\
\text { HUM- } \\
\text { AN }\end{array}$ & $\begin{array}{l}\text { DeXH box protein, } \\
\text { pre-mRNA splicing }\end{array}$ & no reports found & $\begin{array}{l}\text { gene mutation in human } \\
\text { cutaneous SCC, direct } \\
\text { binding with NCL acting } \\
\text { as nuclear interacting } \\
\text { partner }\end{array}$ & 51.5 & 244.4 & 1.3 & 2 \\
\hline ALDH3A2 & $\begin{array}{l}\text { AL3A2 } \\
\text { HUM- } \\
\text { AN }\end{array}$ & $\begin{array}{l}\text { detoxification of } \\
\text { aldehydes } \\
\text { originating from } \\
\text { lipid peroxidation } \\
\text { processes }\end{array}$ & $\begin{array}{l}\text { down-regulated in oral } \\
\mathrm{SCC}\left({ }^{16} \mathrm{O}^{18} \mathrm{O}\right. \\
\text { proteomics analysis } \\
\text { using ESI-ion trap and } \\
\text { MALDI-TOF/TOF MS) }\end{array}$ & direct binding with $\mathrm{EGFR}^{\ddagger}$ & 64.6 & 54.8 & 7.9 & 3 \\
\hline$D S G 1$ & $\begin{array}{l}\text { DSG1- } \\
\text { HUM- } \\
\text { AN }\end{array}$ & desmosome forming & $\begin{array}{l}\text { isoform switch among } \\
\text { DSGs in HNSCC (RNA } \\
\text { analysis) }\end{array}$ & $\begin{array}{l}\text { indirectly down-regulated by } \\
\text { HGF in malignant mela- } \\
\text { noma }\end{array}$ & 175 & 113.7 & 6.9 & 5 \\
\hline KRT9 & $\begin{array}{l}\text { K1C9 } \\
\text { HUM- } \\
\text { AN }\end{array}$ & $\begin{array}{l}\text { intermediate filament of } \\
\text { intracytoplasmatic } \\
\text { cytoskeleton }\end{array}$ & $\begin{array}{l}\text { down-regulated in } \\
\text { HNSCC lymph node } \\
\text { metastasis } \\
\text { (MALDI-Q-TOF } \\
M S / M S \text { ); up-regulated } \\
\text { in NPC } \\
\text { (ESI- } Q-T O F-M S)\end{array}$ & no data found & 1493.3 & 62 & 68.2 & 37 \\
\hline
\end{tabular}

Boldface entries under "Gene symbol" indicate proteins significantly overexpressed in tumor comparing to the adjacent phenotipically normal tissue $(p<0,1)$

Italicized entries under "Gene symbol" indicate proteins with significantly lower abundance in tumor $(\mathrm{p}<0,1)$ comparing to the adjaccent phenotipically normal tissue 
c-MET: hepatocyte growth factor receptor; EGF: epidermal growth factor; EGFR: epidermal growth factor receptor; ECM: extracellular matrix; EMT: endothelial-mesenchymal transition; HGF: hepatocyte growth factor;

HNSCC: head neck cancer squamous cell carcinoma; NFE2L2: nuclear factor, erythroid 2 like 2; NPC: nasopharyngeal carcinoma, ROS: reactive oxygen species; SCC: squamous cell carcinoma

*molecular weight in $\mathrm{kDa}$

**average sequence coverage in percentage

***the average number of peptides each protein was identified with

${ }^{\dagger}$ without identified participating pathways

${ }^{\star}$ with unknown significance

Theoretically, inhibition of TMED2 or its inducer NFE2L2 may suggest a promising tool against HNSCC invasion. NCL can act both as a recruiter and overexpressed protein of EGFR mediated pathways and can facilitate dimerization of EGFR's cytoplasmic tail. Thus NCL overexpression can be both consequence and initiator of EGFR activation. Therefore interfering NCL can also be promising in EGFR-positive HNSCCs, while down-regulation may serve as a marker of anti-EGFR therapy efficacy.

TNC containing EGF-like repeats may serve as targets against EGFR-positive HNSCCs. Inhibiting EGFR results in TNC down-regulation. Considering the diverse correlations between TNC and EGFR, TNC can serve both a potential target in HNSCC and therapeutic response marker in antiEGFR treatment.

DYNLL1-related cytoskeletal rearrangement and tumor cell migration can be theoretically inhibited by anti-HGF therapy, as DYNLL1 shows indirect interaction with HGF in HGF/c-MET pathway in HNSCC.

IPA found indirect inhibition of DSG1 by HGF in malignant melanoma highlighting that DSG1 down-regulation contributes to cell-cell adhesion disruption easing invasion. Thus inhibition of HGF can exert anti-tumor effect with maintaining cell-to-cell junctions via stabilizing desmosomes by DSG1 overexpression. Considering that EGFR pathway shares common signals with HGF-mediated routes resulting redundancy and frequently moderate therapeutic response to anti-EGFR treatment, combined inhibition of EGFR and cMET/HGF pathway is emerging. Interfering redundant pathways (p44/p42 MAPK, PI3K/AKT, STAT) may have the desired anti-cancer effect. Until routinely applied anticancer drug combinations are available simultaneously targeting HGF, EGF and NFE2L2 mediated pathways, inhibition of overexpressed DYNLL, TNC, NCL and TMED2 may exert anti-tumor effect on HNSCC beyond their diagnostic role.

IPA also found unclear interactions. COTL-1 is suggested as tumor-associated protein upregulated on mouse carcinogenesis model. SNRNP200 gene mutation was reported in human cutaneous SCC. IPA found EGFR-ALDH3A2 direct binding with unknown significance. NCL-SNRNP200 direct binding demonstrates NCL's place in RNA metabolism and identifies SNRNP200 as a nuclear interacting partner.

Contrary to previous MS studies, abundance differences were determined using label-free LC/MS based proteomics exclusively on FFPE LHSCC samples. Feasibility of quantitative LS/MS methods on FFPE samples had been
Fig. 1 Note: This data is mandatory. Please provide

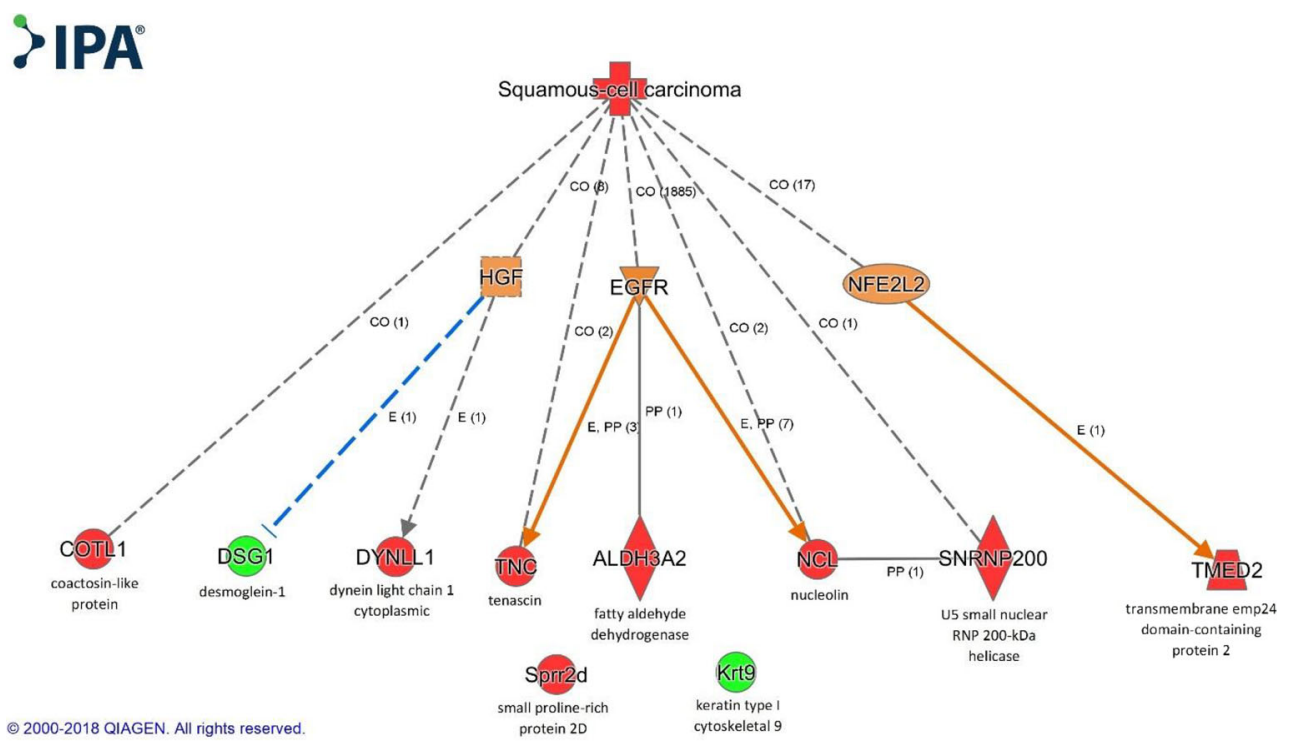

CO: correlation; PP: protein-protein binding; E: expression 
questionable for a long time due to cross-links and formaldehyde induced adducts [9]. Various extraction innovations made protein recovery from FFPE samples as reliable and diagnostically accurate as from fresh-frozen samples [10]. Labeling has several disadvantages compared to label-free technique: protein loss due to each manipulation step, neccessity of prerequisites (e.g. presence of cysteinecontaining peptides) and high costs. These disadvantages also can be bypassed with label-free methods.

Our study also has limitations. Interestingly, IPA did not detect SPRR2D and Krt9. This is probably due to the lack of available IPA data. Continuous amplification of stored data can reveal new interactions. The other drawback of our study is the moderate sample number. It should be noted that our primary aim was to design a pilot study for evaluation of protein abundance differences between LHSCC and adjacent healthy tissue.

\section{Conclusion}

Considering our initial favorable results, this study has clinical relevance. Beside highlighting the proteomic difference between LHSCC and adjacent normal tissue, we found possible LHSCC markers/targets that had not been in focus till date. On the other hand, we proposed the potential in involving large histopathological sample archives taking the reliability of label-free LC/MS on FFPE samples into account facilitating protein discovery. Nevertheless, this easy access to HNSCC samples would make fresh frozen sectioning unneccessary offering a cost-efficient and time-saving solution.

Acknowledgements L.T. is grateful for funding from the National Research Development and Innovation Office (NKFIH PD-121187). L.T. acknowledges support from the János Bolyai Research Scholarship of the Hungarian Academy of Sciences. The work has been supported by GINOP-2.3.3-15-2016-00021.

Funding Information Open access funding provided by University of Pécs.

\section{Compliance with Ethical Standards}

Conflict of Interest The authors declare that they have no conflict of interest.

Informed Consent Informed consent was obtained from all individual participants included in the study.

Open Access This article is licensed under a Creative Commons Attribution 4.0 International License, which permits use, sharing, adaptation, distribution and reproduction in any medium or format, as long as you give appropriate credit to the original author(s) and the source, provide a link to the Creative Commons licence, and indicate if changes were made. The images or other third party material in this article are included in the article's Creative Commons licence, unless indicated otherwise in a credit line to the material. If material is not included in the article's Creative Commons licence and your intended use is not permitted by statutory regulation or exceeds the permitted use, you will need to obtain permission directly from the copyright holder. To view a copy of this licence, visit http://creativecommons.org/licenses/by/4.0/.

\section{References}

1. Marur S, Forastiere AA (2008) Head and neck cancer: changing epidemiology, diagnosis, and treatment. Mayo Clin Proc 83:489501

2. Hashibe M, Brennan P, Chuang SC, Boccia S, Castellsague X, Chen C, Curado MP, Dal Maso L, Daudt AW, Fabianova E, Fernandez L, Wunsch-Filho V, Franceschi S, Hayes RB, Herrero R, Kelsey K, Koifman S, la Vecchia C, Lazarus P, Levi F, Lence JJ, Mates D, Matos E, Menezes A, McClean MD, Muscat J, Eluf-Neto J, Olshan AF, Purdue M, Rudnai P, Schwartz SM, Smith E, Sturgis EM, Szeszenia-Dabrowska N, Talamini R, Wei Q, Winn DM, Shangina O, Pilarska A, Zhang ZF, Ferro G, Berthiller J, Boffetta $P$ (2009) Interaction between tobacco and alcohol use and the risk of head and neck Cancer: pooled analysis in the International Head and Neck Cancer Epidemiology Consortium. Cancer Epidemiol Biomark Prev 18:541-550

3. Argiris A, Karamouzis MV, Raben D, Ferris RL (2008) Head and neck cancer. Lancet 371:1695-1709

4. Erich K, Reinle K, Müller T, Munteanu B, Sammour DA, Hinsenkamp I, Gutting T, Burgermeister E, Findeisen P, Ebert MP, Krijgsveld J, Hopf C (2019) Spatial distribution of endogenous tissue protease activity in gastric carcinoma mapped by MALDI mass spectrometry imaging. Mol Cell Proteomics 18: $151-161$

5. Hanahan D, Coussens LM (2012) Accessories to the crime: functions of cells recruited to the tumor microenvironment. Cancer Cell 21:309-322

6. Paulo JA, Lee LS, Banks PA, Steen H, Conwell DL (2012) Proteomic analysis of formalin-fixed paraffin-embedded pancreatic tissue using liquid chromatography tandem mass spectrometry. Pancreas 41:175-185

7. Carnielli CM, Macedo CCS, De Rossi T, Granato DC, Rivera C, Domingues RR et al (2018) Combining discovery and targeted proteomics reveals a prognostic signature in oral cancer. Nat Commun 9:3598

8. Li L, Zhang Z, Wang C, Miao L, Zhang J, Wang J, Jiao B, Zhao S (2014) Quantitative proteomics approach to screening of potential diagnostic and therapeutic targets for laryngeal carcinoma. PLoS One 9:e90181

9. Metz B, Kersten GF, Hoogerhout P, Brugghe HF, Timmermans HA, de Jong A et al (2004) Identification of formaldehydeinduced modifications in proteins: reactions with model peptides. J Biol Chem 279:6235-6243

10. Fowler CB, O'Leary TJ, Mason JT et al (2013) Toward improving the proteomic analysis of formalin-fixed, paraffin-embedded tissue. Expert Rev Proteomics 10:389-400

Publisher's Note Springer Nature remains neutral with regard to jurisdictional claims in published maps and institutional affiliations. 